\title{
Subcutaneous Dissociative Conscious Sedation (sDCS) an Alternative Method of Anesthesia for Fiberoptic Bronchoscopy
}

\author{
Mihan J. Javid1 ${ }^{*}$, Zoha Alinejad1, Asghar Hajipour'1, Zahra Khazaeipour ${ }^{2}$ \\ ${ }^{1}$ Department of Anesthesiology, Imam Khomeini Medical Center, Tehran University of Medical Sciences \\ (TUMS), Tehran, Iran \\ ${ }^{2}$ Brain and Spinal Cord Injury Research Center, Imam Khomeini Medical Center, Tehran University of Medical \\ Sciences, Tehran, Iran \\ Email: ${ }^{*}$ mihanjavid@yahoo.com
}

Received 13 October 2014; accepted 19 July 2015; published 22 July 2015

Copyright (C) 2015 by authors and Scientific Research Publishing Inc.

This work is licensed under the Creative Commons Attribution International License (CC BY). http://creativecommons.org/licenses/by/4.0/

c) (i) Open Access

\begin{abstract}
Objective: Current randomized clinical trial was conducted to compare the efficacy and side effects of dissociative conscious sedation and conscious sedation in patients under bronchoscopy. Methods: In this randomized clinical trial, 110 patients scheduled for Fiberoptic Bronchoscopy in a training hospital in 2012 were enrolled and randomly assigned to receive either SC ketamine plus IV fentanyl (dissociative conscious sedation) or placebo plus IV fentanyl (conscious sedation) and the efficacy and side effects were assessed and compared. Results: There was significant difference between systolic and diastolic blood pressure and heart rate in two groups and more stability was shown in dissociative conscious sedation group $(P<0.05)$. Also the incidence of cough, the need to extra dose of fentanyl and recall showed less frequency in dissociative conscious sedation group ( $P<0.05)$. Conclusions: Totally, according to the obtained results, it may be concluded that Subcutaneous Dissociative Conscious Sedation (sDCS) in comparison to Conscious Sedation is significantly more efficient accompanied by less side effects in fiberoptic bronchoscopy and using this method is recommended. Implication of the Manuscript: The study was designed in order to evaluate the efficacy of subcutaneous Dissociative Conscious Sedation (sDCS) Method in fiberoptic bronchoscopy.
\end{abstract}

\section{Keywords}

Subcutaneous Dissociative Conscious Sedation, Ketamine, Fiberoptic Bronchoscopy

\footnotetext{
${ }^{*}$ Corresponding author.
}

How to cite this paper: Javid, M.J., Alinejad, Z., Hajipour, A. and Khazaeipour, Z. (2015) Subcutaneous Dissociative Conscious Sedation (sDCS) an Alternative Method of Anesthesia for Fiberoptic Bronchoscopy. Open Journal of Anesthesiology, 5, 149-154. http://dx.doi.org/10.4236/ojanes.2015.57027 


\section{Introduction}

Fiberoptic bronchoscopy is an essential common diagnostic method for lung diseases [1]. The procedure is an invasive procedure and enough sedation is required [2]. Patients who are candidate for bronchoscopy are involved with respiratory problems. Airway manipulation in such patients may result in exacerbation of respiratory problems [3]. However, maintaining the tone of airway muscles and patient cooperation are necessary for successful and safe procedure [4].

To prevent respiratory complication we have to induce light sedation or partial unconsciousness [5] which is accompanied by unsuccessful procedure and non-satisfied patient and operator.

Concomitant use of opioids and benzodiazepines will result in respiratory problem [6]. Intravenous ketamine is an analgesic drug without severe respiratory problems but is not a common modality due to severe hallucination [7]. Subcutaneous Dissociative Conscious Sedation (DCS) is a safe method for painful procedures [8] [9]. It will result in patient's cooperation accompanied by analgesia and enough sedation. Induction of conscious sedation by ketamine via subcutaneous rout was described for the first time by Javid et al in 2009 in "Airway management and Anesthesia in head and neck surgery" congress and then it was introduced as an alternative to airway blocks [8] [10]. Efficacy and safety of this method have been previously established and will result in patients' cooperation. Then this study was designed in order to compare subcutaneous Dissociative Conscious Sedation (sDCS) with Conscious Sedation in fiberoptic bronchoscopy.

\section{Methods and Materials}

In this double-blind randomized clinical trial, 110 patients (age 18 - 65 years and ASA classes of I-III), scheduled for fiberoptic bronchoscopy were enrolled and randomly assigned to receive either SC ketamine plus IV fentanyl (Dissociative Conscious Sedation) or placebo plus IV fentanyl (conscious sedation) and the efficacy and side effects were assessed and compared. The fentanyl dose was $2 \mathrm{ug} / \mathrm{kg}$ and up to $3 \mathrm{ug} / \mathrm{kg}$ if needed. The dose of subcutaneous Ketamine was $0.5 \mathrm{mg} / \mathrm{kg}$. The nasopharyngeal anesthesia was induced by $2 \mathrm{ml}$ of intranasal lidocaine and 4\% lidocaine spray. In non-cooperative subjects, extra doses of fentanyl were administered incrementally up to $3 \mathrm{ug} / \mathrm{kg}$. If the patient was not cooperative enough yet to continue the procedure after administration of extra doses of fentanyl up to $3 \mathrm{ug} / \mathrm{kg}$, the patient was excluded.

Narcotic abuse, uncontrolled hypertension, psychological diseases and untreated ischemic heart disease and increased ICP were the exclusion criteria. The informed consent form was signed by all the patients. All bronchoscopies were performed by the same operator. All SC injections were performed on the anterior aspect of forearm. The procedure was initiated 10 minutes after induction of sedation. The opioid injection was performed titrated.

In cases of nausea and vomiting metoclopramide (10 mg) was administered.

The randomization was by block method and was concealed by anesthesiology resident. The patient and other personnel and also the operator were not informed about the used method for each patient. The consciousness level, heart rate, systolic and diastolic blood pressures, arterial blood oxygen, and electrocardiography were checked. Also the recovery time was recorded in both groups.

Patient's and endoscopist's satisfaction were also evaluated at the end of the procedure. Cough reflex and swallow reflex were evaluated. Apnea, desaturation, nausea and vomiting were recorded.

Data analysis was performed among 110 subjects including 55 patients in intervention group and 55 subjects in control group. Data analysis was performed by SPSS (version 13.0) software [Statistical Procedures for Social Sciences; Chicago, Illinois, USA]. Chi-Square, Fisher, Independent-Sample T, and Repeated-Measure ANOVA test were used and were considered statistically significant at P values less than 0.05 .

\section{Results}

The mean age was 40.6 and 39.2 years in ketamine and placebo groups, respectively (P $>0.05) .74 .5 \%$ and $60 \%$ were male in ketamine and placebo groups, respectively $(\mathrm{P}>0.05)$. As shown in Figures 1-4 the heart rate, oxygen saturation, and systolic and diastolic blood pressures were significantly differed between groups (P < 0.05). All side effects except apnea and swallowing reflex were significantly differed across the groups (Table 1). Patients satisfaction rate was $78.2 \%$ in ketamine group and $12.7 \%$ in placebo group $(P=0.0001)$ and the operator satisfaction rate was $90.2 \%$ and $18.2 \%$ in ketamine and placebo groups respectively $(\mathrm{P}=0.0001)$.

No hallucination was observed in groups. The incidence of recall was significantly lower in ketamine group.

Fentanyl dose was significantly lower in ketamine group (Table 2). 
M. J. Javid et al.

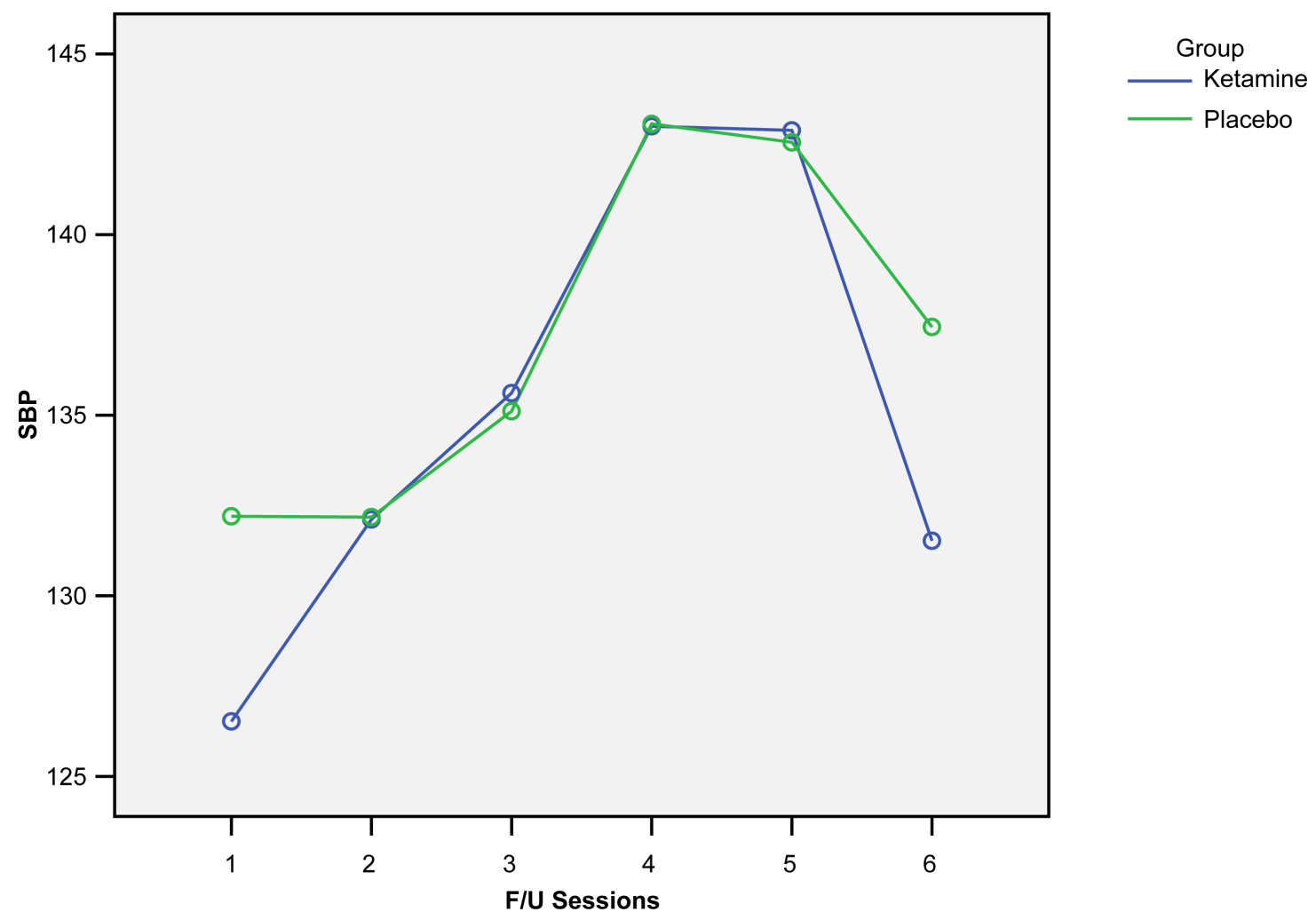

Figure 1. Systolic blood pressure changes across the groups.

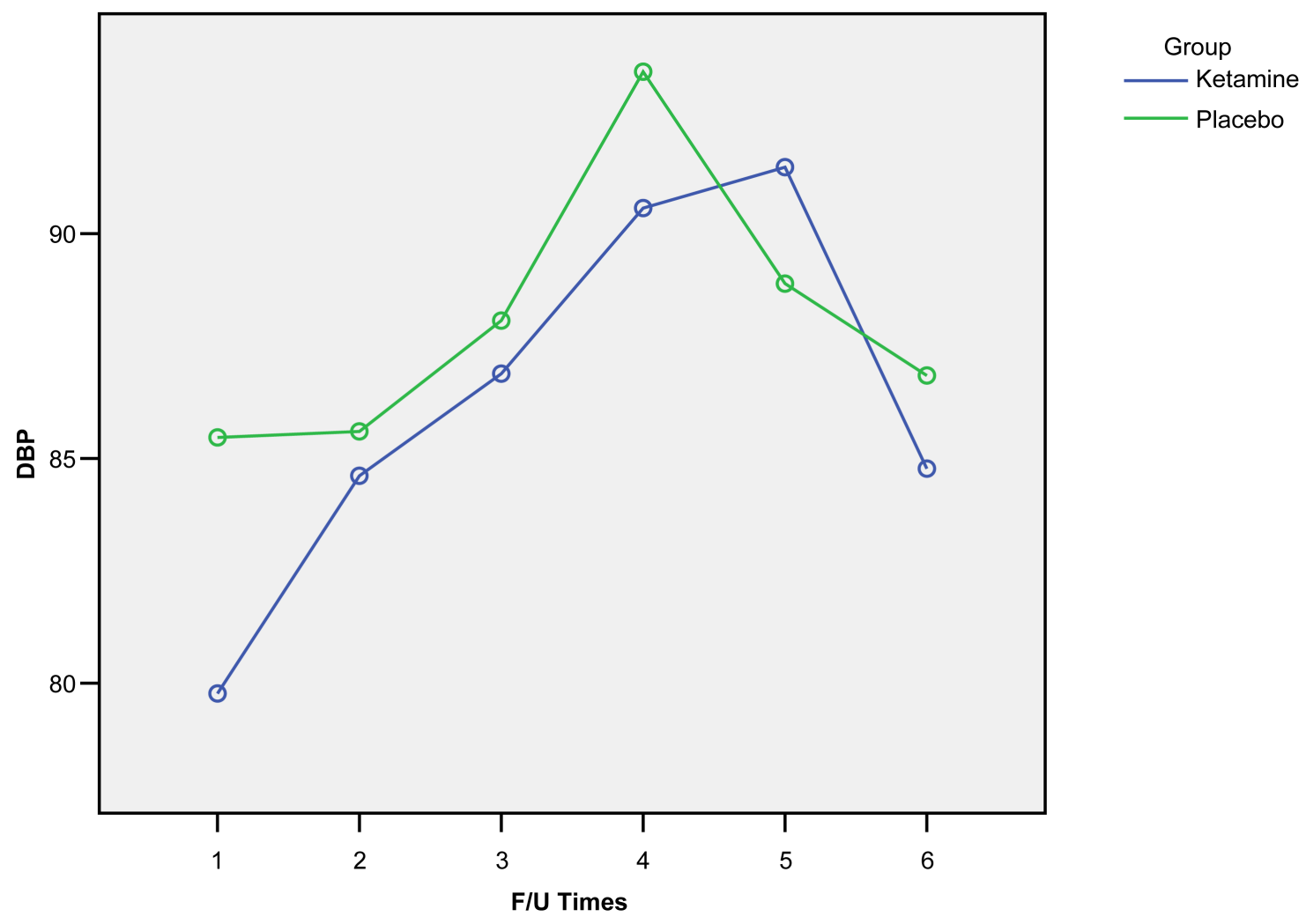

Figure 2. Diastolic blood pressure changes across the groups. 


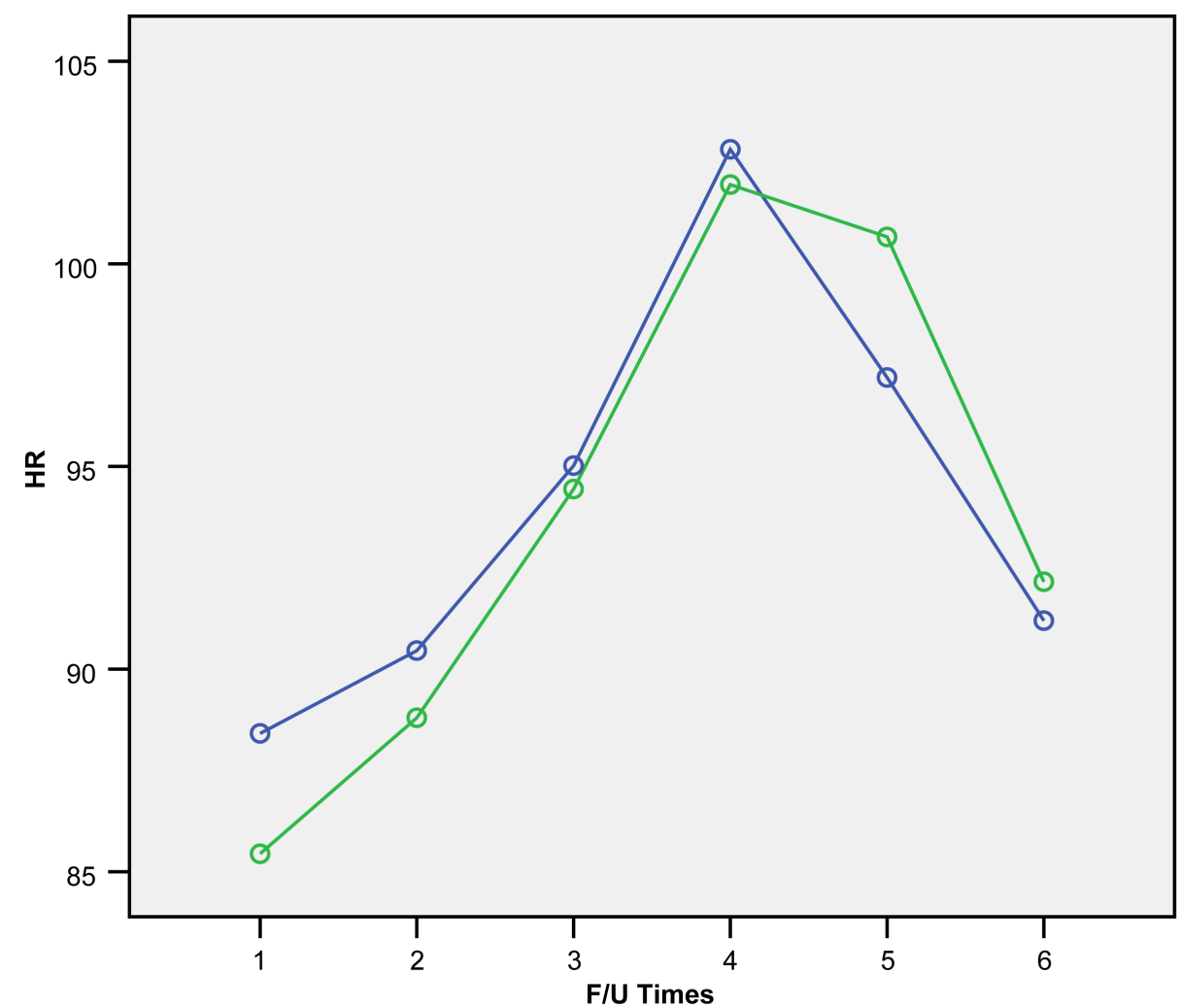

Figure 3. Heart rate changes across the groups.

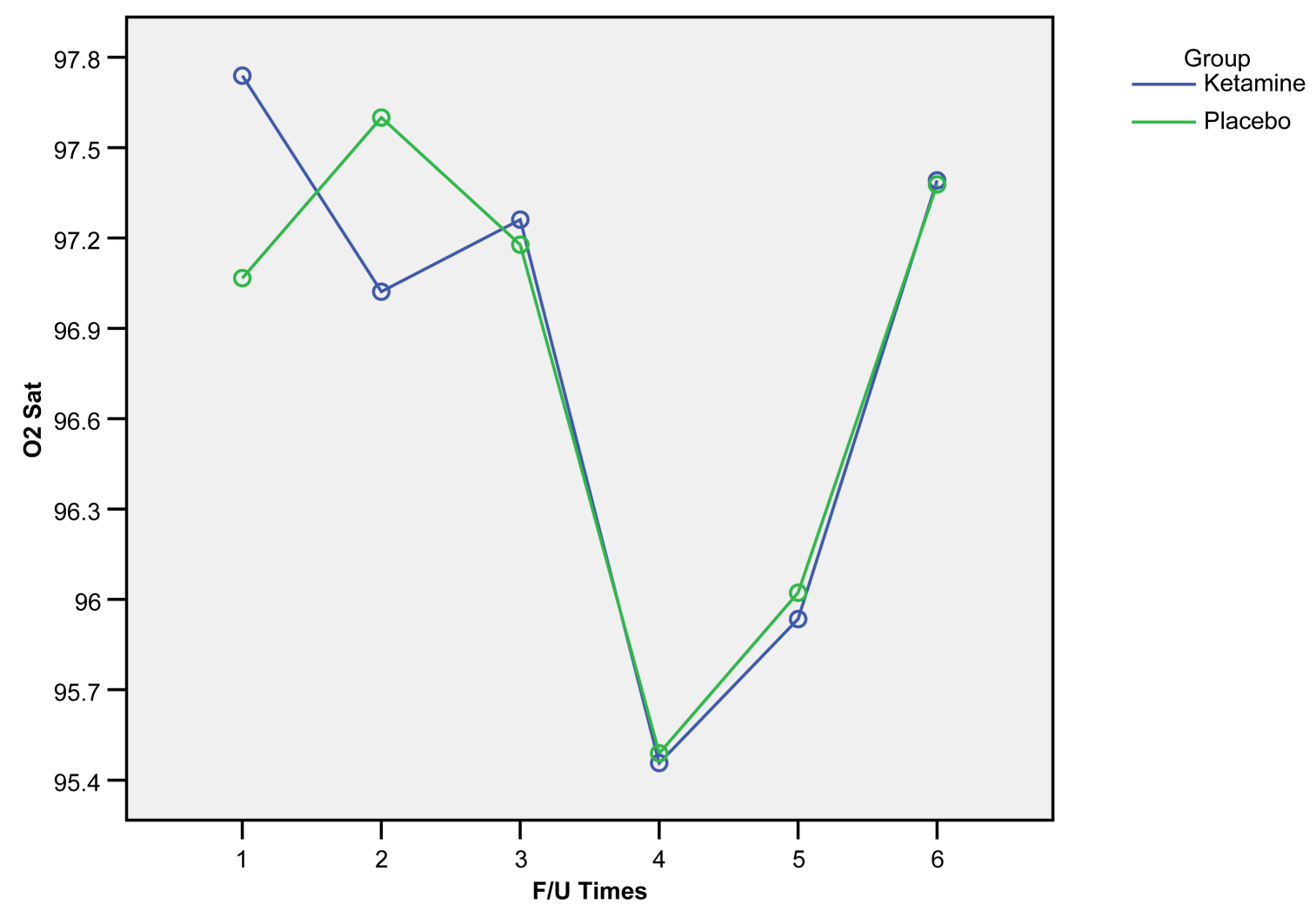

Figure 4. O2 Saturation changes across the groups. 
Table 1. Side effects across the groups.

\begin{tabular}{|c|c|c|c|}
\hline \multirow{2}{*}{ Side effect } & \multicolumn{2}{|c|}{ Group } & \multirow{2}{*}{ P Value } \\
\hline & Ketamine & Placebo & \\
\hline Cough* & $80 \%$ & $94.5 \%$ & 0.022 \\
\hline Swallowing Reflex & $89.1 \%$ & $92.7 \%$ & $>0.05$ \\
\hline Apnea & $5.5 \%$ & $3.6 \%$ & $>0.05$ \\
\hline Nausea and Vomiting & $32.7 \%$ & $12.7 \%$ & 0.012 \\
\hline Recall & $34.5 \%$ & $65.5 \%$ & 0.001 \\
\hline
\end{tabular}

*Cough was severe in $2.3 \%$ of Ketamine group and $59.6 \%$ in control group.

Table 2. Numeric variables in two groups.

\begin{tabular}{cccc} 
Variable & \multicolumn{2}{c}{ Group } & P Value \\
\cline { 2 - 3 } & Ketamine & Placebo & 0.0001 \\
Fentanyl Dose (ug) & 103.7 & 140.9 & 0.05 \\
Recovery Time & 33.2 & 37.7 & 0.7 \\
\hline
\end{tabular}

\section{Discussion}

This study demonstrated that systolic and diastolic blood pressures and heart rate were significantly different between groups and cardiovascular stability was significantly higher in ketamine group. Analgesic consumption was significantly lower in dissociative group $(\mathrm{P}<0.05)$.

Javid et al [8] introduced Dissociative Conscious Sedation instead of general anesthesia for laparoscopic peritoneal catheter insertion. The procedure was optimal in all patients and also the systolic blood pressure was lower in SC ketamine compared with IV ketamine group. The authors were concluded that method was considered as an alternative method for general anesthesia. High cardiovascular stability was observed in sDCS group [9] and this was in congruence with our study. DCS is a safe and optimal method for conscious patients and has been used as an alternative to airway regional blocks [10].

New strategies for difficult airway in surgery and anesthesia would result in more patients' safety and less mortality and morbidity [11]. Ketamine would result in endothelin release and consequently less airway constriction [12]. The SC ketamine would have lower cardiovascular side effects by reduction of intraoperative blood pressure compared with other treatments [8]-[11]. IM injection also showed more cardiac protection compared with IV modality [13] [14]. This method was recommended to use because of less cardiac events [9] [14]. Intravenous ketamine is a good modality but may result in fewer acceptances by both patient and physician [7]. Using SC ketamine in ICU patients demonstrated that fentanyl was accompanied by morestable hemodynamic [9]. This method is safe and optimal and could be recommended as a non-invasive method [10]. Javid et al found the sDCS method suitable in patients with predicted difficult airway [10].

\section{Conclusion}

Totally, according to the obtained results, it may be concluded that use of subcutaneous ketamine plus narcotic (subcutaneous dissociative conscious sedation) in comparison to placebo plus narcotic (conscious sedation) will result in significantly more efficacy and low side effects in fiberoptic bronchoscopy and its use is recommended.

\section{Financial Support}

The study was supported by Tehran University of Medical sciences Research center.

\section{References}

[1] Balfour-Lynn, I.M. and Spencer, H. (2002) Bronchoscopy-How and When? Paediatric Respiratory Reviews, 3, 255-264. http://dx.doi.org/10.1016/S1526-0542(02)00195-1 
[2] De Blic, J. and Scheinmann, P. (1992) Fibreoptic Bronchoscopy in Infants. Archives of Disease in Childhood, 67, 159-161. http://dx.doi.org/10.1136/adc.67.2.159

[3] Adwan, H., Wigfield, C.H., Clark, S. and Barnard, S. (2008) Interventional Bronchoscopy for Benign Tracheobronchial Diseases under Cardiopulmonary Bypass Support: Case Reports and Literature Review. Journal of Cardiothoracic Surgery, 3, 27. http://dx.doi.org/10.1186/1749-8090-3-27

[4] Mak, V.H., Johnston, I.D., Hetzel, M.R. and Grubb, C. (1990) Value of Washings and Brushings at Fibreoptic Bronchoscopy in the Diagnosis of Lung Cancer. Thorax, 45, 373-376. http://dx.doi.org/10.1136/thx.45.5.373

[5] Ninane, V. (2001) Bronchoscopic Invasive Diagnostic Techniques in the Cancer Patient. Current Opinion in Oncology, 13, 236-241. http://dx.doi.org/10.1097/00001622-200107000-00005

[6] Kirkpatrick, M.B., Smith, J.R., Hoffman, P.J. and Middleton, R.M. 3rd. (1992) Bronchoscope Damage and Repair Costs: Results of a Regional Postal Survey. Respiratory Care, 37, 1256-1259.

[7] Rozman, A., Duh, S., Petrinec-Primozic, M. and Triller, N. (2009) Flexible Bronchoscope Damage and Repair Costs in a Bronchoscopy Teaching Unit. Respiration, 77, 325-330. http://dx.doi.org/10.1159/000188788

[8] Javid, M.J., Rahimi, M. and Keshavarzi, A. (2010) Dissociative Conscious Sedation, an Alternative to General Anesthesia for Laparoscopic Peritoneal Dialysis Catheter Implantation: A Randomized Trial Comparing Intravenous and Subcutaneous Ketamine. Peritoneal Dialysis International, 31, 308-314.

[9] Oshima, E., Tei, K., Kayazawa, H. and Urabe, N. (1990) Continuous Subcutaneous Injection of Ketamine for Cancer Pain. Journal of Anesthesia, 37, 385-360.

[10] Javid, M.J. (2011) Subcutaneous Dissociative Conscious Sedation (sDCS) an Alternative Method for Air Way Regional Blocks: A New Approach. BMC Anesthesiology, 11, 19. http://dx.doi.org/10.1186/1471-2253-11-19

[11] Peterson, G.N., Domino, K.B., Caplan, R.A., Posner, K.L., Lee, L.A. and Cheney, F.W. (2005) Management of the Difficult Airway: A Closed Claims Analysis. Anesthesiology, 103, 33-40. http://dx.doi.org/10.1097/00000542-200507000-00009

[12] Sato, T., Hirota, K., Matsuki, A., Zsigmond, E.K. and Rabito, S.F. (1997) The Relaxant Effect of Ketamine on Guinea Pig Airway Smooth Muscle Is Epithelium-Independent. Anesthesia \& Analgesia, 84, 641-647.

[13] Hagihiva, S., Takashina, M. and Mashimo, T. (2008) Application of a Newly Designed Right-Sided, Double-Lumen Endobronchial Tube in Patients with a Very Short Right Mainstem Bronchus. Anesthesiology, 109, 565-568. http://dx.doi.org/10.1097/ALN.0b013e31818344bd

[14] Ostermann, M.E., Keenan, S.P., Seiferling, R.A. and Sibbad, W.J. (2000) Sedation in the Intensive Care Unit: A Systematic Review. Journal of the American Medical Association, 283, 1451-1490.

http://dx.doi.org/10.1001/jama.283.11.1451 